\title{
Lactic Acid Bacteria As Live Vaccines
}

\author{
Annick Mercenier, H. Müller-Alouf, \\ and Corinne Grangette
}

Department of Microbiology of Ecosystems, Institut Pasteur de Lille, 1 rue de Professeur Calmette, 59019 Lille Cedex, France

\begin{abstract}
Mucosal routes for vaccine delivery offer several advantages over systemic inoculation from both immunological and practical points of view. The development of efficient mucosal vaccines therefore represents a top prority in modern vaccinology. One way to deliver protective antigens at the mucosal surfaces is to use live bacterial vectors. Until recently most of these were derived from attenuated pathogenic microorganisms. As an alternative to this strategy, nonpathogenic food grade bacteria such as lactic acid bacteria (LAB) are being tested for their efficacy as live antigen carriers. The LABVAC european research network is presently comparing the vaccine potential of Lactococcus lactis, Streptococcus gordonii and Lactobacillus spp. To date, it has been shown that systemic and mucosal antigen-specific immune responses can be elicited in mice through the nasal route using the three LAB systems under study. Data on successful oral and vaginal immunisations are also accumulating for L. lactis and S. gordonii, respectively. Moreover, the immune responses can be potentiated by co-expression of interleukins. Future areas of research include improvement of local immunisation efficiency, analysis of in vivo antigen production, unravelling of the Lactobacillus colonisation mechanisms and construction of biologically contained strains.
\end{abstract}

\section{Introduction}

The mucosal surfaces of external body cavities correspond to the entry site of most pathogenic organisms. As such, they represent the first line of defense against mucosal infections caused by bacteria, viruses or parasites. The prevention of pathogen penetration relies on non-specific or physiological (mucus layer, peristaltism of the intestinal mucosa, epithelium turnover, acidic and enzymatic environment), microbial (protective normal microflora) and immunological mechanisms. The latter is primarily mediated by antibodies of the immunoglobulin A class ( $\lg A)$ which is by far the most prominent isotype synthesised by the human immune system. The protective immune response against mucosal infections has been shown to strongly depend on the production of secretory $\lg \mathrm{A}(\operatorname{sig} \mathrm{A})$ molecules which are generated locally and transported to the mucosal secretions $(21,47)$. Therefore much effort is devoted today to generate new vaccines which efficiently induce protective local immune responses. This would best be achieved through local administration of relevant antigens, as their systemic delivery generally fails to stimulate the mucosal immune system. However, the vast majority of pure antigens induce low or non-existing immune responses when given orally, due to their poor adsorption or rapid degradation in the gastrointestinal tract and/or to the induction of tolerance by the host. Systems for local delivery of antigens in an immunogenic and protected form are thus actively sought. The development of efficient local (oral) vaccines represents a top priority in several vaccination programs, as they should be associated with fewer side-effects and would facilitate the vaccination of large populations by reducing the need for trained personnel. Moreover, they can prevent carriage of pathogens in the population and have no interference with persisting maternal antibodies in infants $(16,21,44,47)$.

It should be noted that the expression "mucosal vaccines" actually covers two different concepts: on one hand it makes reference to vaccines specifically aimed at inducing local immune responses, essentially of the slgA type; on the other hand, it designates vaccines which are administered through local/mucosal routes but are able to elicit systemic immune responses. In the case of existing parenteral vaccines such as the tetanus vaccine for example, it would be advantageous to raise equally potent systemic immune responses by a local route of administration.

Two major approaches are followed to achieve efficient mucosal delivery of antigens $(16,21,44,47)$. A variety of synthetic (non-living) delivery systems, in which purified antigens are entrapped in microspheres, liposomes, nanoparticules, or ISCOMS, are presently being investigated. An attractive alternative consists in the use of live viral or bacterial vectors for the production of replicative particulate antigens in vivo. This technology, which alleviates the drawbacks of subunit vaccine development, was first described in the early 1980s (9). Inherent difficulties of this approach include the construction of stable immunogenic recombinant strains that synthesise sufficient amounts of antigen in vivo and that offer no risk for the vaccinated individual and the environment. The commonly studied live bacterial vectors are derived from pathogenic (invasive or non-invasive) microorganisms such as Salmonella typhimurium, Listeria monocytogenes, Vibrio cholerae, Mycobacterium bovis BCG. In these cases, stable attenuated mutants that are no longer pathogenic but remain immunogenic, must first be selected or constructed, a step which has proven to be tedious and time consuming in many instances. In addition, attenuated pathogenic strains that retain a residual virulence level are unlikely to be suitable for the vaccination of partially immunocompetent individuals such as infants, elderly people or immunocompromised patients. Also, the immune reaction potentially elicited against the bacterial carrier itself, or the existence of pre-existing antibodies, may reduce the effectiveness of booster doses of vaccine.

An alternative and original way to address these problems is to evaluate the potential of gram-positive bacteria, i.e. lactic acid bacteria ( $L A B)$, to deliver protective antigens at different mucosal surfaces. The choice of $L A B$ 
is based on a number of properties which render them particularly attractive as potential vaccine vehicles. Although in a limited number of cases dietary $L A B$ have been associated with bacterial infections in severely immunocompromised subjects (2), they are considered as GRAS organisms (1) with a very long record of safe oral consumption. They are indeed mostly known for their widespread use as starter strains in food and feed fermentation technology, but also for the probiotic effect that certain species or strains may exert in humans or animals $(15,23)$. For example, it is becoming well established that given strains, mostly belonging to the Lactobacillus genus, are able to colonise cavities such as the mouth, the urogenital or the gastrointestinal tracts, where they play a critical role in maintaining a balanced normal microflora. Certain Lactobacillus strains have already been used, for example, with the aim of preventing or lowering the incidence or recurrent urinary or digestive tract infections (see 15, 23). In addition, most LAB are quite acid resistant and certain strains are able to effectively survive passage through the stomach. These microorganisms are, in principle, particularly suited for easy oral or local administration and the absence of LPS in their cell wall virtually eliminates the risk of endotoxic shock. Moreover, the food industry has a long and detailed experience in the large scale production and preservation of these microorganisms (47).

Research on gram-positive bacterial vehicles is quite recent and has focussed mainly on indigenous or food bacteria such as LAB (Lactococcus, Streptococcus and Lactobacillus), non-pathogenic species of Staphylococcus (S. carnosus and S. xylosus) (40), and attenuated strains of Listeria monocytogenes which is especially suited to induce an $\mathrm{MHC}$ class I restricted cytotoxic immune response (12).

\section{The LABVAC European Network}

Although LAB offer many potential advantages as live vaccine vehicles, there were initially no indications that live non-invasive bacterial vectors could be used to induce immune responses against the foreign antigen that they produced. The novelty of the proposed research approach led to a number of basic questions that needed to be addressed (Table 1).

By nature, these points cover three interconnected areas: microbiology, molecular biology and immunology. The selection of model vaccine species or strains represents a critical step as the basic choice of using colonising (transiently implanted in the normal microflora) versus non-colonising (very short persistence in the host) isolates leads to quite different systems. In the first case, it is expected that a continuous in vivo synthesis of the antigen at the desired mucosal surface will trigger the underlying immune system. It might be speculated that a high level of synthesis will not be a prerequisite, especially when using immunostimulatory $L A B$ strains. In the second case, the non-colonising $L A B$ may be considered as live microparticles that should be pre-loaded with the antigen and that will thus rely on high-level expression of protective antigens. Existing knowledge cannot predict if the optimal presentation of the antigen, a parameter which is known to affect its immunogenicity, will be identical or not in both systems. In the case of colonisers, strains appropriate for future human use have to be selected on the basis of safety, metabolic and physiological criteria. In addition, any of the potential vaccine strains should obviously be genetically amenable, in order to allow the expression of protective antigens or epitopes in different cellular locations (i.e. intracellularly, extracellularly or cell-surface exposed). Even though the genetics of $L A B$ has progressed impressively during the last fifteen years, strain-specific optimisation of expression, secretion and targeting vectors still require investigation. Concerning immunology, it is necessary to analyse the nature and the intensity of the immune response in relation to the mode of antigen presentation, the immunisation route and the nature of the bacterial vector.

The different aspects of this novel approach have been covered through the coordinated effort of European laboratories (listed in Table 2) organised in two successive research networks (contracts $\mathrm{BIO} 2-\mathrm{CT} 94-3055$ and $\mathrm{BIO4-}$ CT96-0542), focussing on a common model system outlined in Table 3 . Three LAB bacterial hosts are being evaluated as potential vaccine vehicles: Lactococcus lactis, a cheese starter strain, as a prototype of a non-colonising strain for which more sophisticated genetic tools exist; lactobacilli, which are able to colonise given body cavities; and Streptococcus gordonii, an oral commensal bacterium of human origin for which a stable antigen presentation system had been established. The progress achieved for each of these hosts in terms of microbiology, molecular biology and immunology are summarised below. The European project is concentrated on two main model antigens, of bacterial and viral origins respectively, in order to allow a controlled comparison of the three bacterial systems under study. The first one is the tetanus toxin fragment C (TTFC), a 47kDa non-toxic polypeptide carrying the ganglioside-binding domain. Even though tetanus is not a mucosally associated disease, TTFC is a useful model because of its well-established immunogenicity and the availability of a lethal mouse challenge model permitting evaluation of the protective significance of the immune response generated (8). Since protection relies essentially in this case on the induction of a systemic immune response, this is a good way to evaluate the capability of a

Table 1. Development of $L A B$ as Live Vaccine Vehicles: Questions to Address

- Are food or "commensal" bacteria given at relatively high doses recognised as "self" or "non self" by the immune system of the host?

Which kind of immune response (local/systemic, humoral/cellular, Th1/Th2, MHC-classl/-class II restricted) can be elicited by non-pathogenic noninvasive live vectors?

What is the immunomodulation capacity of different LAB?

Should a foreign antigen expressed by recombinant LAB remain intacellular, be secreted or surface-bound?

What level of antigen expression will be necessary to elicit a significant immune response?

What level of antigen expression will be necessary to elicit a significant immune response?

How easily can a recombinant bacterium establish itself transiently in an equilibrated endogenous microflora?

How easily can a recombinant bacterium establish itself transiently in an equil
What is the fate of LAB strains given locally? How stable are they in vivo? 


\begin{tabular}{|c|c|c|}
\hline Annick MERCENIER (coordinator) & INSTITUT PASTEUR DE LILLE & FRANCE \\
\hline Peter H. POUWELS & TNO NUTRITION AND FOOD RESEARCH INSTITUTE & THE NETHERLANDS \\
\hline Jean DELCOUR & UNIVERSITE CATHOLIQUE DE LOUVAIN & BELGIUM \\
\hline John K. COLLINS & UNIVERSITY COLLEGE CORK & IRELAND \\
\hline Gianni POZZI & UNIVERSITA DI SIENA & ITALY \\
\hline Jeremy M. WELLS, Richard W.F. LE PAGE & UNIVERSITY OF CAMBRIDGE & GREAT BRITAIN \\
\hline Erwin SABLON & INNOGENETICS N.V. & BELGIUM \\
\hline Willem M. de VOS & WAGENINGEN AGRICULTURAL UNIVERSITY & THE NETHERLANDS \\
\hline Erik REMAUT & UNIVERSITEIT GENT & BELGIUM \\
\hline Patricia CONWAY & UNIVERSITY OF NEW SOUTH WALES & AUSTRALIA \\
\hline
\end{tabular}

mucosal delivery system to elicit a systemic humoral immune response. The second antigen is the gp50 protein of the porcine pseudorabies virus (Aujeszky's disease virus, ADV), a pathogen which infects animals through the respiratory tract and which could be best inactivated by mucosal immune responses (22). The choice of gp50 is motivated by the necessity to evaluate the potential of $L A B$ as live vaccines to target viral mucosa-associated diseases. In this case as well, bioactivity of the induced antibody responses can be evaluated by challenging mice or pigs by the ADV.

In the course of the project, pharmacokinetic studies in humans were performed with a limited number of nonrecombinant lactic acid bacterial strains which were shown to be genetically amenable and able to persist in the mouse intestine and/or vagina.

\section{Lactococcus lactis}

Unlike the other LAB being developed as vaccine delivery vehicles, Lactococcus lactis does not colonise the digestive tract of man or animals. In mice, there is only a passive transit (persistence time $<24 \mathrm{~h}$ ) of $L$. lactis through the digestive tract (11) while in humans, lactococci pass through the gut within 3 days (20). As it is expected that $L$. lactis would be likely to have only a limited capacity to produce and secrete antigens in vivo, attention has been focussed on expressing antigens intracellularly, or as fusions to the cell wall anchoring domains of cell surfaceassociated proteins, so that the bacteria are pre-loaded with antigen before they are used for immunisation. In order that immunogenic quantities of antigen can be delivered to the mucosal immune system a high-level inducible expression system which exploits the properties of the $E$. coli T7 bacteriophage RNA polymerase has first been developed for $L$. lactis (pLET vectors). Using the lactococcal T7 system, a number of heterologous antigens have been expressed intracellularly at high levels $(2-20 \%$ total soluble cell protein) in L. lactis (e.g. tetanus toxin fragment $C$ (TTFC), diphtheria toxin fragment $\mathrm{B}$, the $28 \mathrm{KDa}$ immunogen of Shistosoma mansoni [P28]), as well as a variety of TTFC fusion proteins including for example TTFCHIV-gp120V3 loop fusion proteins (for reviews, see 5, 26, $45,46)$. Additional pLET vectors were further designed to secrete the antigen (up to $3 \mathrm{mg} / \mathrm{L}$ ) or anchor it to the cellsurface. Expression vectors which incorporate constitutively active promoters of low to medium strength have also been employed for antigen expression (5). One such vector designated pTREX1 has been used to express TTFC and P28 at levels of $1-3 \%$ of total cell protein (5, $46)$. It is envisaged that these constitutive expression vectors will be more suitable for the expression of antigens which are membrane associated or which show some insolubility or toxicity to bacterial cells when formed at high levels. It was observed, for example, that high expression of TTFC in the cytoplasm of $L$. lactis ultimately kills the cell (5).

The most complete immunological study has been conducted with recombinant $L$. lactis producing the TTFC $(5,26,45,46)$. Initially, recombinant $L$. lactis expressing TTFC as membrane-anchored, as an intracellular or as a secreted protein, were administered subcutaneously,

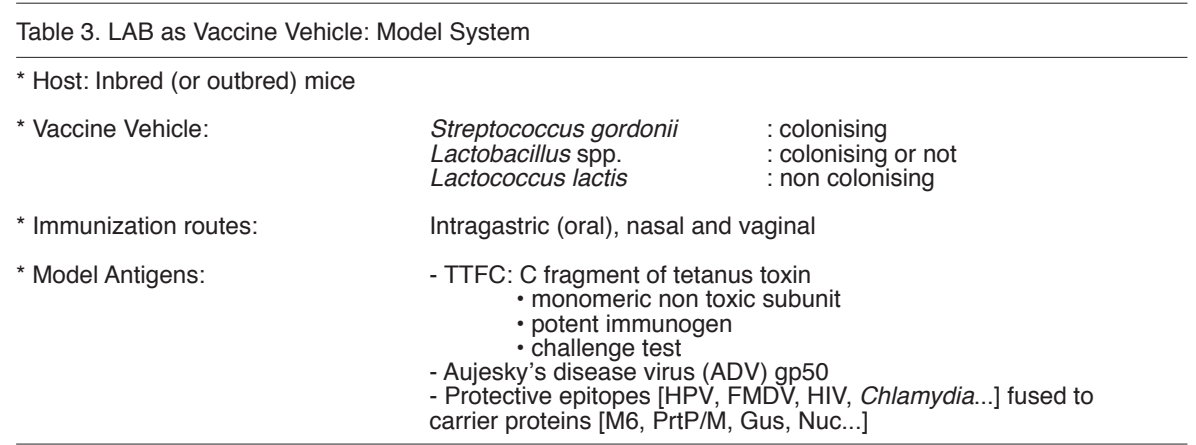


without adjuvant, into mice. It was shown that all three lactococcal TTFC expressor strains were able to elicit antibodies which protected the mice from lethal toxin challenge (i.e. 5-20 $\times L_{50}$ of tetanus toxin). The dose of $L$. lactis required to elicit protective antibody responses appeared to be primarily dependent on the amount of antigen produced by the different recombinant strains. However, when only a limited amount of TTFC was expressed, protective antibodies were more readily elicited when the TTFC was anchored to the cell membrane. In further experiments, mice were immunised by the oral and intranasal routes. Nasal inoculation of mice with strain UCP1050 (expressing TTFC intracellularly using the lactococcal T7 system) led to a significant IgG serum antibody response which protected $75 \%$ of the mice from lethal challenge with tetanus toxin $\left(20 \times L_{50}\right)$. The antibody titers were similar wether live, mytomycin C- or formalintreated $L$. lactis were used (37). It was next shown that mice can also be immunised orally with $L$. lactis strains producing TTFC at high levels (T7 expression system) or at a ten-fold lower level (pTREX1). TTFC-specific serum antibody responses of both the IgG1 and IgG2a isotypes were induced and significantly, but transiently, elevated levels of anti-TTFC IgA antibodies were detected in faeces and gut secretions. Even though the antibody titers were lower than those following nasal immunisation, the protective efficacy was similar (37).

A similar study has been performed with the glutathione S-transferase (P28) of the parasite Schistosoma mansoni (3). The P28 antigen has been efficiently expressed in $L$. lactis either separately or as a fusion to TTFC, and the immunogenicity of these antigens when expressed in $L$. lactis has been proven by systemic and local immunisations (see 5, 26, 46).

The studies conducted with the second model antigen of the LABVAC network, the ADV gp50, have initially been hampered by the instability of the recombinant plasmids carrying the corresponding gene in expression hosts such as Escherichia coli and L. lactis. Therefore, a synthetic gene with a codon usage adapted to $L$. lactis and lacking the transmembrane domain has been assembled (Wells, J. M. et al., unpublished results). Its successfull expression in L. lactis (Rush, C.M., Wells, J.M. et al., unpublished) and L. plantarum (Pavan, S., Chagnaud, P. et al., unpublished) relied upon the use of the nisin inducible expression system (19). The immunogenicity of the recombinant strains, which produce high amounts of gp50, is presently under investigation (Sablon, E., personal communication).

Whether lactococci can also be used to deliver cytokines to the immune system has been investigated recently. The murine IL2 and IL6 genes were first expressed in $L$. lactis and the recombinant strains were shown to secrete fully active interleukins in the culture supernatants at a level of $0.9 \mathrm{mg} / \mathrm{L}$ (41). In a second stage, L. lactis strains accumulating TTFC in the cytoplasm and secreting IL2 or IL6 concomitantly were constructed and used to immunise mice intranasally. A strong adjuvant effect was observed only with the live recombinant strains. The anti-TTFC serum IgG titers increased more rapidly and were 10 to 15 fold higher as compared to those generated by immunising with strains producing TTFC only. In contrast, the level of the anti-lactococcal immune responses were not enhanced by coexpression of the cytokines (42).

\section{Streptococcus gordonii}

Streptococcus gordonii is a gram-positive bacterium that is a member of the normal microflora of the human oral cavity. It has been shown to efficiently colonise the mouse oral and vaginal cavities while it persists only transiently in the digestive tract of this host $(24,25,26,27,29,35)$. The genetic system that allows expression of heterologous antigens on the surface of S. gordonii strain "Challis", which is naturally competent for genetic transformation, has been extensively reviewed $(24,27,35)$. It is based on chromosomal integration of recombinant DNA encoding the vaccine antigen fused to the gene of the Streptococcus pyogenes surface protein M6. The latter is a fibrillar surface protein anchored to the bacterial cell by the $\mathrm{C}$-terminal domain. Translational fusions with the M6 protein gene are constructed in E. coli using plasmid vectors that can integrate into the chromosome of specifically engineered S. gordonii recipient strains. Transformation with recombinant insertion vectors results in integration of the gene fusion downstream from a strong chromosomal promoter. The M6: :antigen fusion protein is anchored to the $S$. gordonii membrane and expressed on the bacterial surface at levels reaching up to 10,000 molecules per cell (Pozzi G., personal communication). During growth, some antigen is also released in the external medium such that S. gordonii in fact delivers both particulate and soluble antigens to the immune system. When the M6 anchoring region is not included in the fusion protein, secretion yields up to $5 \mathrm{mg} / \mathrm{L}$ are achieved. Recombinant $S$. gordonii have been constructed that express on the surface heterologous proteins ranging in size from 15 to 441 amino acids. Antigens of a variety of viral, bacterial, and eukaryotic origin, including the E7 protein of human papilloma virus type 16, the V3 domain of HIV-1 gp120, an allergen (Ag5.2) from hornet venom, ovalbumin, the surface proteins $(\mathrm{F}$ and $\mathrm{H})$ of the measles virus, the $B$ subunit of the heat labile toxin (LTB) of E. coli and TTFC (unpublished data) have been expressed using this system $(26,35,46)$. In fact, nine chromosomal integration sites leading to strong expression have been identified and, recently, a recombinant strain expressing two different antigens concomitantly at the cell surface has been constructed (35).

The immunogenicity of the recombinant vaccine strains was tested mainly in the mouse model, although recent experiments were also conducted in monkeys (see below). In summary, it was shown that recombinant $S$. gordonii colonising the murine oral cavity and vagina are capable of inducing local and systemic antibodies against the heterologous antigens expressed on the bacterial cell surface. A single dose of $S$. gordonii was used to inoculate the animals, and it was found that: (i) stable colonisation was achieved both in the oro-phayngeal and vaginal cavities of inbred and outbred mice; (ii) recombinant strains were equally effective as wild-type in colonising mice leading to a high percentage of animals colonised at high numbers; (iii) the colonisation was inoculum-independant in a range of doses equal to $10^{7}-10^{9} \mathrm{cfu}$; (iv) antigen expression was stable both in vitro and in vivo; (v) antigenspecific local $(\lg A)$ and systemic $(\lg G 1$ and $\lg G 2 a$ predominently) antibodies were produced; (vi) the immune response depended upon effective bacterial colonisation, since killed recombinant bacteria did not induce a local response $(25,26,27,35)$. 
It should be noted that the first evidence that a recombinant commensal bacterium can be used as a live vaccine vector was obtained with $S$. gordonii (24). The most complete immunological studies were conducted with recombinant strains displaying M6::E7 or M6 ::Ag5.2 at their cell surface, investigating two main routes of administration (i.e. the oral and vaginal; [25, 26, 27, 35, 46]). In the latter case, S. gordonii offers the advantage with respect to other strategies developed for vaginal immunisation to provide the host with a prolonged exposure to the antigen and therefore seems to be an excellent vaccine candidate to prevent the spread of sexually transmitted diseases. Interestingly, anti-E7 IgA responses were detected in vaginal washes 8 weeks after administration of the recombinant strains producing M6::E7 in coincidence with the sudden clearance of bacteria from the mouse vagina which may be related to a strong antibacterial immune response $(25,27)$. The only intragastric immunisation described so far used strains producing LTB. Even though the bacteria did not colonise the intestinal mucosa, they were effective in inducing both serum $\lg G$ and faecal $\lg A(26)$.

Successful vaginal immunisation of cynomologous monkeys has recently been described with recombinant S. gordonii producing E7 or HIV1-V3 at their cell surface. Although no vaginal colonisation was observed in this host, repeated administrations led to the induction of specific serum $\lg G$, vaginal $\lg A$ and $T$ cells specific for $E 7$ or V3 (27).

Finally, recent results indicate that $S$. gordonii is phagocytosed by dendritic cells which are consequently activated $(26,36)$. This is an important observation as dendritic cells represent efficient antigen-presenting cells responsible for generating primary $\mathrm{T}$ cell responses and acting as sentinels for recognition of invading organisms in tissues facing the external environment.

While $S$. gordonii performs very well as a bacterial vector, there are still safety issues to address before licensing such a system for human use. First, the vector itself was formerly classified as Streptococcus sanguis (17). Second, the fusion partner, the $S$. pyogenes M6 protein, has long be considered as a virulence determinant even though the internal sequences inducing human tissue cross-reactive antibodies are not included in the final constructions. Finally, the genetic system in use leads to the chromosomal integration of the gene fusion and the associated drug resistance marker (35).

\section{Lactobacilli}

The development of Lactobacillus spp. as vaccine vehicles is inherently more complex than the two above described approaches, but offers potential advantages. In contrast to $L$. lactis and S. gordonii, for which the studies conducted so far have been concentrated on a single strain (strains MG1363 [10] and Challis [17], respectively), the choice of lactobacilli leads to numerous candidate vaccine strains. This is a direct consequence of the fact that this genus is widespread and contains over 60 species, remarkably diverse in their genotype (mole \% G+C 32-52\%), their metabolism or phenotypic properties, their distribution in nature, and their use in industry. Two types of Lactobacillus may, in theory, be considered as potential antigen delivery systems, the so-called "commensal" strains and the "dietary" ones. The first, when properly selected, could combine health-promoting properties with the capacity to colonise host-specific (humans or animals) body cavities such as the oral cavity, oesophagus, stomach, small and large intestine, vagina and urethra. The second, mainly used as starters for the preparation of fermented milk, meat or vegetable products, are presumably different from the lactobacilli belonging to the indigenous microflora, at least in their ability to populate mucosal niches, thus leading to an approach similar in concept to the L. lactis system. It has also been reported that different Lactobacillus species or strains vary substantially in their immunoadjuvant and immunostimulation capacities $(30,33,34)$. This aspect should be taken into consideration when choosing the vaccine strain as it is a natural way to potentiate the immune reaction raised against the heterologous antigen produced by recombinant lactobacilli. It should be mentioned, however, that studies have not yet been reported in which the adjuvanticity or immunomodulation of L. lactis, $S$. gordonii and different lactobacilli have been compared.

It is thus evident that when developing lactobacilli as vaccine vehicles, the choice of the carrier strain is critical. Independently of their colonisation ability, the selected strains have to be innocuous and genetically amenable. In the case of colonisers, it is generally considered that their capacity to adhere to the relevant epithelial surfaces is an important property. Adhesion can be mediated through direct adherence to the antigen sampling cells such as $M$ cells, to epithelial cells or to mucus, or even through coaggregation with resident bacteria, leading to an increased competition with the endogenous bacterial community and to sustained antigen stimulus. Both in vitro and animal models have been used to select or screen for adherent Lactobacillus strains (for reviews see 33, 34, 39). However until recently in vivo studies in the targeted host were hampered by the lack of appropriate strain identification tools, which can now be circumvented by using molecular typing methods. There is scarce evidence nowadays that in vitro predictions are applicable in vivo. Nevertheless, converging data indicate that colonisation is host- and tissue- or site-specific such that it is unlikely that a unique strain will constitute an ideal vector to deliver protective antigens to different hosts or to different mucosal cavities within the same host $(34,39)$. The strain selection criteria should thus take the final target into account as in the case of probiotics (13).

In the first European project, P. Marteau, J.K. Collins and coworkers have compared the survival rate and gut transit time of four non-recombinant chromosomally marked $\left(\right.$ Rif $^{r} \mathrm{Sm}^{\mathrm{r}}$ ) lactic acid bacterial strains. L. lactis MG1363, Lactobacillus fermentum KLD, Lactobacillus plantarum NCIMB 8826 and Lactobacillus salivarius UCC 433118 were given orally to human volunteers as a fermented milk product. The two latter strains were found far superior to the former in their ability to survive the passage through the stomach and to reach high viable counts in the ileum where the Peyer's patches are located. None of the strains colonised the gastrointestinal tract permanently (Marteau P. et al., in preparation). Even though it sounds most appropriate to isolate the final candidate strains from the targeted host with the hope of minimising individual variation in colonisation, for preliminary studies in mice a variety of strains of human or murine origin can be used as they are able to colonise at least two body cavities of 
this animal model. For example, S. gordonii was shown to persist for several weeks in the oral cavity and the vagina, while L. paracasei LbTGS1.4 (vaginal murine isolate) and L. plantarum NCIMB 8826 (human saliva isolate) persisted in the gut or the vagina for over a week (29). A direct comparison of different mucosal immunisation routes is thus possible with the same candidate vaccine strain, illustrating the flexibility offered by the mouse model.

The importance of selecting the most appropriate Lactobacillus strain at the onset of the project is also linked to the strong strain-specificity of the currently used gene cloning and expression tools $(32,34)$. As could be anticipated from the genetic diversity of Lactobacillus genus, optimal translation, transcription and targeting sequences vary with the species and might even be straindependent. The progress in the genetics of lactobacilli (for reviews $18,28,32,38$, Chapter 6 ) is more recent than that reported for lactococci and S. gordonii. However, for the strains studied within the LABVAC network, concerted efforts led to heterologous gene expression levels close to those obtained in lactococci $(33,34,38,45)$. Different antigens were produced in the cytoplasm (up to a few percent of total protein content), in the culture medium (up to $13 \mathrm{mg} / \mathrm{L}$ [14]) or at the cell surface (up to 10000 molecules [34]) of strains such as $L$. paracasei LbTGS1.4, $L$. plantarum NCIMB 8826, L. zeae ATCC393 and $L$. plantarum 256. Recent improvements in gene expression included the development of plasmid expression vectors of increased stability $(33,34)$ and chromosomal integration systems which target specific or random loci and that are based on a variety of non-replicative or unstable plasmids or, alternatively, on recombinant conjugative transposons $(27,38)$. The latter offer the possibility to rapidly test the expression of the specific antigen in a variety of recipient strains, but may lead to integrants which carry an antibioresistance marker and in which a gene(s) essential for persistence or immunomodulation is (are) inactivated. An alternative and elegant system, based on a nonreplicative plasmid, has been derived from the one described by Dupont et al., (6) in which non-disruptive integration is achieved in the tRNA ${ }^{\text {ser }}$ locus. Hols and colleagues (in preparation) constructed an integration vector, especially tailored for $L$. plantarum, that can lead to insertion either at the tRNA ${ }^{\text {ser }}$ or at the L-LDH locus. Inactivation of the L-LDH does not impair the growth of $L$. plantarum in vitro or in vivo. As the recombinant plasmid carries the antigen encoding DNA as a transcriptional translational fusion with the $L$-Idh gene, a second in vivo homologous recombination event leads to excisants containing solely the heterologous gene and no antibiotic marker. Both systems were used successfully to produce antigens in lactobacilli. Recombinant transposons allowed Rush \& Pozzi (38) to express the E. coli LTB at the cell surface of different lactobacilli. Using the plasmid system described above, stable integration of the M6::gp41E (gp41E is an HIV-1 derived epitope; 31 ) or the TTFC encoding gene in the chromosome of $L$. plantarum NCIMB 8826 was achieved. In both cases, integration into the $L$ Idh gene led to higher production levels than insertion at the tRNA ${ }^{\text {ser }}$ locus. The integrants produced only 4 to 5 times lower antigen doses than the corresponding recombinant strains carrying multicopy plasmids (Hols P., Delcour J. et al., Geoffroy M.-C., Mercenier A. et al., in preparation). The expression of TTFC in different cellular compartments of a number of different Lactobacillus strains was also performed with the expression vector system developed by the TNO (34). It should be noted that improvement of expression levels often relied on modification of the translation initiation region (7) or translational fusion with well expressed endogenous genes $(32,34,38)$.

Few regulatable promoters are available for lactobacilli. As in the case of lactococci, constitutive promoters did not allow stable expression of the ADV gp50 gene. Therefore the nisin inducible expression system originally designed for $L$. lactis (19) was implemented in L. plantarum NCIMB 8826 (Pavan S., et al., submitted. This required integration of the sensor and regulatory genes, nisK and nisR, into the chromosome of this host and to optimise the induction conditions. The nisin system turned out to be very efficient as it led to high level expression of gp50, TTFC, and GFP (Green Fluorescent Protein from Aequorea victoria;4) upon nisin induction. Since the antigen production level can be controlled by the induction conditions, it will be possible to investigate the effect of the quantity of antigen delivered on the magnitude and duration of the immune response. The $\mathrm{GFP}^{+}$strains, on the other hand, represent an ideal tool to perform in vivo studies as they do not require addition of exogenous substrate or co-factor to be fluorescent. Their usefulness has recently been demonstrated both in vitro (phagocytosis by macrophages) and in vivo (intranasal or intragastric administration to mice) (49). It is also intended to use the GFP marker to follow the survival of potentially contained strains in the environment.

As in the case of lactococci and S. gordonii, a variety of antigens have been expressed in lactobacilli $(26,33$, $34,38,46)$. Although the function of lactobacilli as adjuvant or carrier was established early on, the immunogenicity of recombinant strains by the intraperitoneal route was demonstrated relatively recently (see 33,34 ). The first evidence of successful local administrations with these vectors awaited the construction of strains producing higher amounts of the studied antigens $(28,34,38,46)$. Recent experiments conducted within the LABVAC network (unpublished results) confirmed, for example, that like the corresponding lactococcal strains, all lactobacilli producing TTFC at the level of a few percent of total cellular protein content, including the $L$. plantarum NCIMB8826 integrant, induced serum IgG and local IgA responses after nasal administration. A controlled comparison of the TTFCproducing $L A B$ strains by the oral route has been undertaken as well.

Ongoing work linked to the development of Lactobacillus as live vaccine carrier includes the selection of strains appropriate for human use (Collins J.K. et al., unpublished results), identification of adhesion factors (34), use of S-layers for antigen presentation (34) and construction of biologically contained strains (Hols P., Delcour J. et al., personal communication).

\section{Conclusion}

While bacterial vaccine vectors have been studied experimentally for over 15 years, it is interesting to note that no live, recombinant bacterial vectors are in commercial human or veterinary use today even though clinical studies are in progress with attenuated $V$. cholerae and $S$. typhimurium (see 43). Although there are multiple reasons for this situation (43), the safety of vaccine strains 
is a key issue at the level of vaccinated individuals and environmental spread. Both aspects could be alleviated by using properly selected and contained LAB strains. To date the results obtained with $L A B$ are very encouraging as they show that these non-pathogenic, non-invasive bacterial vectors are capable of delivering antigen to the mucosal and systemic immune systems generating specific antibody responses in serum and secretions. While both gut colonisers and non-colonisers seem to work equally well by the systemic and nasal routes, the importance of colonisation or adhesion in oral administration is still under investigation. Notably, these carriers seem to induce a mixed Th1/Th2 type immune response.

The existing data indicate that $L A B$ have low innate antigenicity even though several strains clearly exhibit immunodajuvant properties $(5,34)$. Moreover, the antibacterial immune response was found to be lower when recombinant lactococci were used rather than the wild-type (5). This might explain why, so far, there is no indication that tolerance is systematically induced by LAB carriers. It might be postulated that this will be the case as long as the expression level and immunogenicity of the heterologous protein produced by the LAB is sufficient to stimulate the immune system of the host. Moreover, immunogens expressed by $L A B$ are presented to the immune sytem in particulate form and should thus be less prone to induce local tolerance than soluble antigens (48).

In the scope of vaccine development, a number of key points remain to be addressed. It is important to pursue a detailed analysis of the immune response generated in relation to the mode of antigen presentation and the immunisation route and to further improve the efficiency of $\mathrm{LAB}$ as antigen carriers in order to finally compare them to the other bacterial vectors under development. It is also necessary to gain knowledge about the in vivo antigen production level, the molecular mechanisms of adhesion and the fate of locally administered LAB. These studies have actually started concomitantly with the construction of biologically-contained food grade strains. Last but not least, as in the case of probiotics, well-controlled studies have to be performed in humans or animals in order to clarify the colonisation capacity of properly selected Lactobacillus strains and their interaction with the immune system and the endogenous microflora of the host. Although this delivery system is still preliminary in nature, it may be considered as a promising vehicle not only for antigens, but also for biologically active compounds such as immunomodulators, antibodies, enzymes or peptides.

\section{Acknowledgements}

We thank our colleagues from the LABVAC networks and from the NIZO for allowing the presentation of unpublished results and for very stimulating and constructive interactions. We deeply acknowledge the support of the European Union (Contracts BIO2-CT94-3055 and BIO4-CT960542) which permitted to organise a concerted research effort in this field. The LABVAC laboratories benefit also from additional individual research grants. We are grateful to $G$. Tannock and C. Locht for critical reading of the manuscript. Warm thanks to the IPL Bacteriology laboratory : P. Chagnaud, M.-C. Geoffroy, D. Goudercourt, S. Pavan and N. Reveneau.

\section{References}

1. Adams, M.R. and P. Marteau. 1995. On the safety of lactic acid bacteria. Int. J. Food Microbiol. 27: 263264.

2. Aguirre, M. and M.D. Collins. 1993. Lactic acid bacteria and human clinical infection. J. Appl. Bacteriol. 75: 95109.

3. Capron, A., G. Riveau, J.M. Grzych, D. Boulanger, M. Capron, and R. Pierce. 1995. Development of a vaccine strategy against human and bovine schistosomiasis. Background and update. Mem. Inst. Oswaldo Cruz, Rio de Janeiro 90: 235-240.

4. Chalfie, M., Y. Tu, G. Euskirchen, W.W. Ward, and D.C. Prasher. 1994. Green fluorescent protein as a marker for gene expression. Science 263: 802-805.

5. Chamberlain, L.M., J.M. Wells, K. Robinson, K.M. Schofield, and R.W.F. Le Page. 1997. Mucosal immunisation with recombinant Lactococcus lactis., p. 83-106. In G. Pozzi and J.M. Wells (ed.), Gram-positive bacteria as vaccine vehicles for mucosal immunisation. Biotechnology Intelligence Unit. Landes, Austin, U.S.A.

6. Dupont, L., B. Boizet-Bonhoure, M. Coddeville, F. Auvray, and P. Ritzenthaler. 1995. Characterisation of genetic elements required for site-specific integration of Lactobacillus delbrueckii subsp. bulgaricus bacteriophage mv4 and construction of an integrationproficient vector for Lactobacillus plantarum. J. Bacteriol. 177: 586-595.

7. Dutot, P. 1996 Evaluation des lactobacilles comme vecteurs vivants de vaccination. $\mathrm{PhD}$ thesis, Université Louis Pasteur de Strasbourg, France.

8. Fairweather, N.F., V.A. Lyness, and D.J. Maskell. 1987. Immunisation of mice against tetanus toxin with fragments of tetanus toxin synthesised in Escherichia coli. Infect. Immun. 55: 2541-2545.

9. Formal, S.B., L.S. Baron, D.J. Kopecko, O. Washington, C. Powell, and C.A. Life. 1981. Construction of a potential bivalent vaccine strain : introduction of Shigella sonnei form I antigen genes into the galE Salmonella typhi Ty21a typhoid vaccine strain. Infect. Immun. 34: 746-750.

10. Gasson, M.J. 1983. Plasmid complements of Streptococcus lactis NCDO 712 and other lactic streptococci after protoplast-induced curing. J. Bacteriol. 154: 1-9.

11. Gruzza, M., M. Fons, M.F. Ouriet, Y. Duval-Iflah, and R. Ducluzeau. 1994. Study of gene transfer in vitro and in the digestive tract of gnotobiotic mice from Lactococcus lactis strains to various strains belonging to human intestinal flora. Microb. Releases 2: 183-189.

12. Guzman, C.A., S. Weiss, and T. Chakraborty. 1997. Listeria monocytogenes - A promising vaccine carrier to evoke cellular immune reponses, p. 145-173. In G. Pozzi and J.M. Wells (ed.) Gram-positive bacteria as vaccine vehicles for mucosal immunisation. Biotechnology Intelligence Unit. Landes, Austin, U.S.A.

13. Havenaar, R., B. Ten Brink, and J.H.J. Huis in't Veld. 1992. Selection of strains for probiotic use. p. 209224. In R. Fuller (ed.), Probiotics, the scientific basis. Chapmann and Hall, London, UK.

14. Hols, P., P. Slos, P. Dutot, J. Reymund, P. Chabot, B.Delplace, J. Delcour, and A. Mercenier. 1997. Efficient secretion of the model antigen M6-gp41E in 
Lactobacillus plantarum NCIMB 8826. Microbiol. 143: 2733-2741.

15. Holzapfel, W.H., P. Haberer, J. Snel, U. Schillinger, and J.H.J. Huis in't Veld. 1998. Overview of gut flora and probiotics. Int. J. Food Microbiol. 41: 85-101.

16. Husband, A.J. 1993. Novel vaccination strategies for the control of mucosal infection. Vaccine 11: 107-112.

17. Kilian, M.L., L. Mikkelsen, and J. Henrichsen. 1989. Taxonomic study of viridans streptococci: Description of Streptococcus gordonii sp. nov. and ammended descriptions of Streptococcus sanguis (White and Niven 1946), Streptococcus oralis (Bridge and Sneath 1982), and Streptococcus mitis (Andrews and Horder 1906). Int. J. Syst. Bacteriol. 39: 471-484.

18. Klaenhammer, T.R. 1995. Genetics of intestinal lactobacilli. Int. Dairy J. 5: 1019-1058.

19. Kleerebezem M., M.M. Beerthuyzen, E.E. Vaughan, W.M. de Vos, and O.P. Kuipers. 1997. Controlled gene expression systems for lactic acid bacteria: Transferable nisin-inducible expression cassettes for Lactococcus, Leuconostoc, and Lactobacillus spp. Appl. Environ. Microbiol. 63: 4581-4584.

20. Klijn, N., A.H. Weerkamp, and W.M. de Vos. 1995. Genetic marking of Lactococcus lactis shows its survival in the human gastrointestinal tract. Appl. Environ. Microbiol. 61: 2771-2774.

21. Lamm, M.E. 1997. Interaction of antigens and antibodies at mucosal surfaces. Ann. Rev. Microbiol. 51: 311-340.

22. Marchioli, C., R. J. Yancey, J. G. Timmins, B. R. Young, and D. A. Povendo. 1988. Protection of mice and swine from pseudorabies virus-induced mortality by administration of pseudorabies virus-specific mouse monoclonal antibodies. Am. J. Vet. Res. 49: 860-864.

23. Marteau, P. and J.C. Rambaud. 1993. Potential of using lactic acid bacteria for therapy and immunomodulation in man. FEMS Microbiol. Rev. 12: 207-22.

24. Medaglini, D., G. Pozzi, T.P. King, and V.A. Fischetti. 1995. Mucosal and systemic immune responses to a recombinant protein expressed on the surface of the oral commensal bacterium Streptococcus gordonii after oral colonisation. Proc. Natl. Acad. Sci. USA. 92: 6868-6872.

25. Medaglini, D., C.M. Rush, P. Sestini, and G. Pozzi. 1997. Commensal bacteria as vectors for mucosal vaccines against sexually transmitted diseases: Vaginal colonisation with recombinant streptococci induces local and systemic antibodies in mice. Vaccine 15: $1330-1337$.

26. Medaglini, D., S. Ricci, T. Maggi, C.M. Rush, R. Manganelli, M.R. Oggioni, and G. Pozzi. 1997. Recombinant gram-positive bacteria as vehicles of vaccine antigens. Biotechnol. Ann. Rev. 3: 297-312.

27. Medaglini, D., M. Oggioni, and G. Pozzi. 1998. Vaginal immunisation with recombinant gram-positive bacteria. Amer. J. of Reprod. Immunol. 39:199-208.

28. Mercenier, A., P.H. Pouwels, and B.M Chassy. 1994. Genetic engineering of lactobacilli, leuconostocs and Streptococcus thermophilus, p. 252-293. In M.J. Gasson and W.M. de Vos (ed.), Genetics and Biotechnology of Lactic Acid Bacteria. Blackie Academic and Professional, Glasgow, Scotland.

29. Mercenier, A., P. Dutot, P. Kleinpeter, M. Aguirre, P.
Paris, J. Reymund, and P. Slos. 1996. Development of lactic acid bacteria as live vectors for oral or local vaccines. Adv. Food Sci. 18: 73-77.

30. Miettinen, M., J. Vuopio-Varkila, and K. Varkila. 1996. Production of human Tumor Necrosis Factor Alpha, Interleukin-6, and Interleukin-10 is induced by lactic acid bacteria. Infect. Immun. 64: 5403-5405.

31. Muster, T., F. Steindl, M. Purtscher, A. Trkola, A. Klima, G. Himmler, F. Ruker, and H. Katinger. 1993. A conserved neutralising epitope on gp41 of human immunodeficiency virus type 1. J. Virol. 67: 6642-6647.

32. Pouwels, P.H. and R.J. Leer. 1993. Genetics of lactobacilli, plasmids and gene expression. Anton. van Leeuwen. 65: 85-107.

33. Pouwels, P.H., R.J. Leer, and W.J.A. Boersma. 1996. The potential of Lactobacillus as a carrier for oral immunisation : development and preliminary characterisation of vector systems for targeted delivery of antigens. J. Biotechnol. 44: 183-192.

34. Pouwels, P.H., R.J. Leer, M. Shaw, M.-J. Heijne den Bak-Glashouwer, F.D. Tielen, E. Smit, B. Martinez, J. Jore, and P.L. Conway. 1998. Lactic acid bacteria as antigen delivery vehicles for oral immunisation purposes. Int. J. Food Microbiol. 41: 155-167.

35. Pozzi, G., M.R. Oggioni, and D. Medaglini. 1997. Recombinant Streptococcus gordonii as a live vehicle for vaccine antigens, p. 35-60. In G. Pozzi and J.M. Wells (ed.), Gram-positive bacteria as vaccine vehicles for mucosal immunation. Biotechnology Intelligence Unit. Landes, Austin, U.S.A.

36. Rescigno, M., C. Citterio, M. Théry, M. Rittig, D. Medaglini, G. Pozzi, S. Amigorena, and P. RicciardiCastagnoli. 1998. Bacteria-induced neo-biosynthesis, stabilisation, and surface expression of functional class I molecules in mouse dendritic cells. Proc. Natl. Acad. Sci. USA 95: 5229-5234.

37. Robinson, K., L.M. Chamberlain, K.M. Schofield, J.M. Wells, and R.W.F. Le Page. 1997. Oral vaccination of mice against tetanus with recombinant Lactococcus lactis. Nature Biotechnol. 15: 653-657.

38. Rush, C.M., A. Mercenier, and G. Pozzi. 1997. Expression of vaccine antigens in Lactobacillus, p. 107144. In G. Pozzi and J.M. Wells (ed.), Gram-positive bacteria as vaccine vehicles for mucosal immunisation. Biotechnology Intelligence Unit. Landes, Austin, U.S.A.

39. Salminen, S., E. Isolauri, and E. Salminen. 1996. Clinical uses of probiotics for stabilising the gut mucosal barrier: successful strains and future challenges. Anton. van Leeuwen. 70: 347-358.

40. Stahl, S., P. Samuelson, M. Hansson, C. Andréoni, L. Goetsch, C. Libon, S. Liljeqvist, E. Gunneriusson, H. Binz, T. Ngoc Nguyen, and M. Uhlén. 1997. Development of non-pathogenic staphylococci as vaccine delivery vehicles, p. 61-81. In G. Pozzi and J.M. Wells (ed.), Gram-positive bacteria as vaccine vehicles for mucosal immunisation. Biotechnology Intelligence Unit. Landes, Austin, U.S.A.

41. Steidler, L., J.M. Wells, J. Raeymaekers, J. Vandekerckhove, W. Fiers, and E. Remaut. 1995. Secretion of biologically active murine interleukin-2 by Lactococcus lactis subsp. lactis. Appl. Environ. Microbiol. 61: 1627-1629.

42. Steidler, L., K. Robinson, L. Chamberlain, K.M. Schofield, E. Remaut, R.W.F. Le Page, and J.M. Wells. 
1998. Mucosal delivery of murine interkeukin-2 (IL-2) and IL- 6 by recombinant strains of Lactococcus lactis coexpressing antigen and cytokine. Infect. Immun. 66: 3183-3189.

43. Strugnell, R., C.Simmons, O. Wijburg, T. Uren, D. Drew, and S.Dunstan. 1998. Bacterial vectors: Why have they failed to deliver? Australasian Biotechnol. 8: 86-90.

44. Walker, R.I. 1994. New strategies for using mucosal vaccination to achieve more effective immunisation. Vaccine 12 : 387-400.

45. Wells, J.M., P.M. Norton., and R.W.F. Le Page. 1995. Progress in the development of mucosal vaccines based on Lactococcus lactis. Int. Dairy Journal 5: 10711079.

46. Wells, J.M., K. Robinson, L.M. Chamberlain, K.M. Schofield, and R.W.F. Le Page. 1996. Lactic acid bacteria as vaccine delivery vehicles. Anton. van Leeuwen. 70: 317-330.

47. Wells, J.M. and G. Pozzi. 1997. An overview of grampositive bacteria as vaccine vehicles for mucosal immunisation, p. 1-8. In G. Pozzi and J.M. Wells (ed.), Gram-positive bacteria as vaccine vehicles for mucosal immunisation. Biotechnology Intelligence Unit. Landes, Austin, U.S.A.

48. Wold, A.E., U.I.H. Dahlgren, L.A.Hanson, I. MattsbyBaltzer, and T. Midvedt. 1989. Difference between bacterial and food antigens in mucosal immunogenicity. Infect. Immun. 57: 2666-2673.

49. Geoffroy, M.-C., Guyard, C., Quatannens, B., Pavan, S., Lange, M., and Mercenier, A. 2000. Use of Green Fluorescent protein to tag Lactic Acid bacterium strains under development as live vaccine vectors. Appl. Environ. Microbiol. 66: 383-391. 


\section{Further Reading}

Caister Academic Press is a leading academic publisher of advanced texts in microbiology, molecular biology and medical research. Full details of all our publications at caister.com

- MALDI-TOF Mass Spectrometry in Microbiology Edited by: M Kostrzewa, S Schubert (2016) www.caister.com/malditof

- Aspergillus and Penicillium in the Post-genomic Era Edited by: RP Vries, IB Gelber, MR Andersen (2016) www.caister.com/aspergillus2

- The Bacteriocins: Current Knowledge and Future Prospects Edited by: RL Dorit, SM Roy, MA Riley (2016)

www.caister.com/bacteriocins

- Omics in Plant Disease Resistance Edited by: V Bhadauria (2016) www.caister.com/opd

- Acidophiles: Life in Extremely Acidic Environments Edited by: R Quatrini, DB Johnson (2016) www.caister.com/acidophiles

- Climate Change and Microbial Ecology: Current Research and Future Trend

Edited by: J Marxsen (2016)

www.caister.com/climate

- Biofilms in Bioremediation: Current Research and Emerging Technologies

Edited by: G Lear (2016)

www.caister.com/biorem

- Microalgae: Current Research and Applications Edited by: MN Tsaloglou (2016) www.caister.com/microalgae

- Gas Plasma Sterilization in Microbiology: Theory, Applications, Pitfalls and New Perspectives Edited by: H Shintani, A Sakudo (2016) www.caister.com/gasplasma

- Virus Evolution: Current Research and Future Directions Edited by: SC Weaver, M Denison, M Roossinck, et al. (2016) www.caister.com/virusevol

- Arboviruses: Molecular Biology, Evolution and Control Edited by: N Vasilakis, DJ Gubler (2016) www.caister.com/arbo

- Shigella: Molecular and Cellular Biology Edited by: WD Picking, WL Picking (2016) www.caister.com/shigella

-Aquatic Biofilms: Ecology, Water Quality and Wastewater Treatment

Edited by: AM Romaní, H Guasch, MD Balaguer (2016)

www.caister.com/aquaticbiofilms

- Alphaviruses: Current Biology

Edited by: S Mahalingam, L Herrero, B Herring (2016)

www.caister.com/alpha

- Thermophilic Microorganisms

Edited by: F Li (2015)

www.caister.com/thermophile
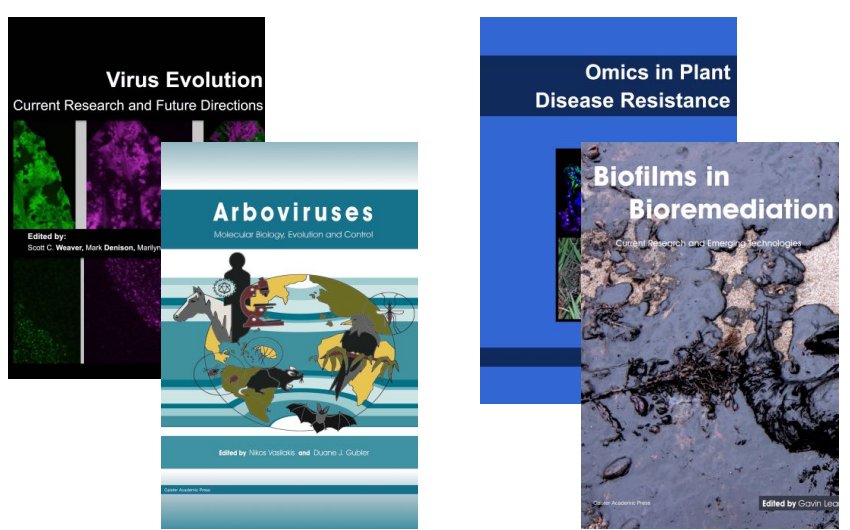
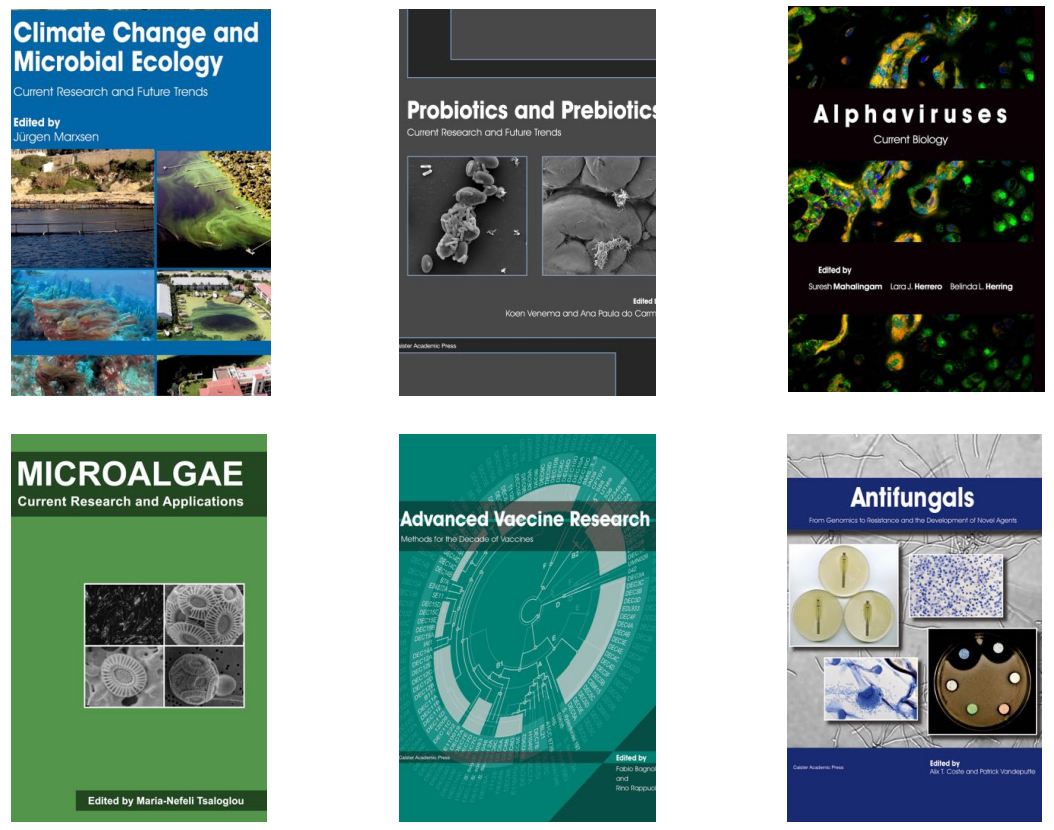

- Flow Cytometry in Microbiology: Technology and Applications Edited by: MG Wilkinson (2015) www.caister.com/flow

- Probiotics and Prebiotics: Current Research and Future Trends Edited by: K Venema, AP Carmo (2015) www.caister.com/probiotics

- Epigenetics: Current Research and Emerging Trends Edited by: BP Chadwick (2015) www.caister.com/epigenetics2015

- Corynebacterium glutamicum: From Systems Biology to Biotechnological Applications

Edited by: A Burkovski (2015)

www.caister.com/cory2

- Advanced Vaccine Research Methods for the Decade of Vaccines

Edited by: F Bagnoli, R Rappuoli (2015)

www.caister.com/vaccines

- Antifungals: From Genomics to Resistance and the Development of Novel Agents

Edited by: AT Coste, P Vandeputte (2015)

www.caister.com/antifungals

- Bacteria-Plant Interactions: Advanced Research and Future Trends Edited by: J Murillo, BA Vinatzer, RW Jackson, et al. (2015) www.caister.com/bacteria-plant

\section{- Aeromonas}

Edited by: J Graf (2015)

www.caister.com/aeromonas

- Antibiotics: Current Innovations and Future Trends

Edited by: S Sánchez, AL Demain (2015)

www.caister.com/antibiotics

- Leishmania: Current Biology and Contro Edited by: S Adak, R Datta (2015) www.caister.com/leish2

- Acanthamoeba: Biology and Pathogenesis (2nd edition) Author: NA Khan (2015)

www.caister.com/acanthamoeba2

- Microarrays: Current Technology, Innovations and Applications Edited by: Z He (2014)

www.caister.com/microarrays2

- Metagenomics of the Microbial Nitrogen Cycle: Theory, Methods and Applications

Edited by: D Marco (2014)

www.caister.com/n2 